\title{
Thromboxane $\mathbf{B}_{2}$ Production by Fetal and Neonatal Platelets: Effect of Idiopathic Respiratory Distress Syndrome and Birth Asphyxia
}

\author{
PEKKA KÄÄPÄ, ${ }^{(24)}$ LASSE VIINIKKA, AND OLAVI YLIKORKALA \\ Departments of Pediatrics and Clinical Chemistry, University of Oulu, Oulu, and Department of Obstetric and \\ Gynecology, University of Helsinki, Helsinki, Finland
}

\section{Summary}

To study the production of proaggregatory thromboxane $\mathbf{A}_{2}$ $\left(\mathrm{TxA}_{2}\right)$ by fetal and neonatal platelets, blood specimens were collected from umbilical cords immediately after delivery at term $(n=22)$, from newborn infants during the first 10 days of life $(n$ $=85)$, from infants between 1 and 3 months of age $(n=14)$, and from healthy adults $(n=18)$. The blood samples were allowed to clot spontaneously at $+37^{\circ} \mathrm{C}$ for $60 \mathrm{~min}$, and the concentrations of thromboxane $B_{2}\left(T \times B_{2}\right)$, a stable metabolite of $T \times A_{2}$, in the sera were measured by radioimmunoassay and expressed as nanograms of $\mathrm{TxB}_{2} / \mathbf{1 0}^{6}$ platelets.

Platelet $\mathrm{TxB}_{2}$ generation in term infants at the age of 1 day $\left(1.344 \pm 0.253 \mathrm{ng} / \mathbf{1 0}^{6}\right.$ platelets, mean $\left.\pm \mathrm{SE}, n=9\right)$ was higher than that in cord blood $\left(0.634 \pm 0.042 \mathrm{ng} / 10^{6}\right.$ platelets, $\left.n=22\right)$, or in infants of $1-3$ months of age $\left(0.881 \pm 0.099 \mathrm{ng} / 10^{6}\right.$ platelets, $n=14)$, or in adults $\left(0.869 \pm 0.062 \mathrm{ng} / 10^{6}\right.$ platelets, $\left.n=18\right)$. Increase in $\mathrm{TxB}_{2}$ generation following birth was seen already at the age of $1 \mathrm{~h}\left(1.076 \pm 0.114 \mathrm{ng} / \mathbf{1 0}^{6}\right.$ platelets, $\left.n=9\right)$. $\mathrm{TxB}_{2}$ synthesis in preterm infants $\left(1.032 \pm 0.136 \mathrm{ng} / \mathbf{1 0}^{6}\right.$ platelets, $n=$ 10) did not differ from that in term infants on the 1st day of life, and idiopathic respiratory distress syndrome had no effect on it $\left(1.029 \pm 0.079 \mathrm{ng} / 10^{6}\right.$ platelets, $\left.n=19\right)$. Severe birth asphyxia was accompanied by reduced $\mathrm{TxB}_{2}$ formation $(0.564 \pm 0.201 \mathrm{ng} /$ $10^{6}$ platelets, $n=7$ ).

The mode of delivery, the birth weight, and the sex of the infants were not related to $T \times B_{2}$ production on the 1st day of life. Neither maternal pre-eclampsia nor epidural analgesia during labor affected neonatal $\mathbf{T X B}_{2}$ generation. The bleeding time also did not correlate with $\mathrm{TxB}_{2}$ formation. It is suggested that a rapid, but transient stimulation in $\mathrm{TxA}_{2}$ synthesis after birth may contribute to the neonatal adaptation of vascular platelet function.

\section{Abbreviations}

IRDS, idiopathic respiratory distress syndrome

TxA $\mathbf{A}_{2}$, thromboxane $\mathbf{A}_{2}$

$\mathbf{T x B}_{2}$, thromboxane $\mathbf{B}_{2}$

$\mathbf{P G I}_{2}$, prostacyclin

The hemostatic mechanisms mature throughout gestation (2); nevertheless, the platelets of healthy term neonates are characterized by impaired aggregation and release reaction in response to physiologic stimuli $(13,17,22)$. This platelet dysfunction may be important to apparently healthy preterm infants, since it is suggested to correlate with intracranial bleeding in these infants (16). In addition, in many neonatal disorders, such as birth asphyxia and IRDS, deficient platelet function may be clinically significant, since these conditions are frequently accompanied by a hemorrhagic tendency (6).

$\mathrm{TxA}_{2}$, the main derivative of arachidonic acid in the platelets, is the most potent endogenous proaggregatory agent which also causes vasoconstriction (5). It is produced and released during platelet aggregation and rapidly converted to its stable metabolite $\mathrm{TxB}_{2}(4,5)$. Although the significance of $\mathrm{TxA}_{2}$ in adults has been exhaustively studied (4), little is known about $\mathrm{TxA}_{2}$ in the human fetus and neonate although birth causes profound adaptations in platelet vascular functions (3). We therefore studied platelet $\mathrm{TxB}_{2}$ production in cord blood, in healthy newborn infants, and in infants with severe birth asphyxia and IRDS.

\section{SUBJECTS AND METHODS}

Subjects. Eighty-five infants were studied during the first 10 days of life (Table 1). Thirty-three term (37 weeks of gestation or more) and 20 preterm (less than 37 weeks of gestation) infants were healthy, whereas 25 preterm infants had IRDS, the diagnosis of which was based on the following criteria: grunting, retractions of the chest, cyanosis, reticulogranular pattern on the chest x-ray and need of ventilatory support for a period longer than $48 \mathrm{~h}$. The birth weight, gestational age and Apgar scores of the distressed infants were comparable with those of the healthy preterm infants (Table 1). Seven infants (five term, two preterm) were severely asphyxiated at birth (Apgar scores of 3 or less at $1 \mathrm{~min}$ and 6 or less at $5 \mathrm{~min}$, as well as in need of assisted ventilation for at least $10 \mathrm{~min}$ after birth) because of placental abruption ( $n$ $=2$ ) and cord compression $(n=5)$. In addition, blood samples were collected from umbilical cords in 22 term deliveries immediately after placental expulsion. We also studied nine healthy term infants at the age of $1 \mathrm{~h}, 14$ healthy infants between 1 and 3 months of age and 18 healthy adults.

Thrombocytopenia (platelet count under $100 \times 10^{9} /$ liter), hyperbilirubinemia (serum total bilirubin $>170 \mu \mathrm{mol} /$ liter), and maternal or neonatal ingestion of drugs known to interfere with prostaglandin synthesis indicated exclusion from the study. The study was approved by the local Committee of Ethics. An informed consent was obtained from the parents or subjects in every case.

Sampling and Analytical Methods. Neonatal blood samples (1-2 $\mathrm{ml})$ were collected into dry tubes from the descending aorta via an umbilical arterial catheter or from a peripheral vein without stasis in connection with routine clinical monitoring. Similar blood samples from older infants and adults were taken by venipuncture. Cord blood was drawn from the umbilical cord 
Table 1. Clinical data of the healthy term and preterm infants and infants with IRDS or severe birth asphyxia*

\begin{tabular}{|c|c|c|c|c|}
\hline & \multirow{2}{*}{$\begin{array}{l}\text { Gestational } \\
\text { age (weeks) }\end{array}$} & \multirow{2}{*}{$\begin{array}{c}\text { Birth weight } \\
\text { (g) }\end{array}$} & \multicolumn{2}{|c|}{ Apgar score } \\
\hline . & & & $1 \mathrm{~min}$ & $5 \mathrm{~min}$ \\
\hline Term infants $(n=33)$ & $39(37-42)$ & $3530(1900-4490)$ & $9(6-10)$ & $9(7-10)$ \\
\hline Healthy preterm infants $(n=20)$ & $33.5(27-36)$ & $1880(1180-2850)$ & $7(5-9)$ & $9(6-10)$ \\
\hline Preterm infants with IRDS $(n=25)$ & $34(26-36)$ & $2230(1210-3370)$ & $8(4-9)$ & $9(6-10)$ \\
\hline Infants with severe asphyxia $(n=7)$ & $40(32-41)$ & $3530(2190-3830)$ & $2(1-3)$ & $4(2-5)$ \\
\hline
\end{tabular}

* Median values are shown with ranges in parentheses.

vein immediately after expulsion of the placenta. Blood was allowed to clot at $37^{\circ} \mathrm{C}$ for $60 \mathrm{~min}$, and the serum was then separated and the concentration of $\mathrm{TxB}_{2}$ was measured by radioimmunoassay (20). The intra-assay and interassay coefficients of variation were between 6.7 and $9.7 \%$, and $18.6 \%$, respectively. The amounts of $\mathrm{TxB}_{2}$ released into serum during spontaneous clotting correlate closely with those released during induced aggregation in platelet-rich plasma (20). To avoid the effect of individual variation in platelet counts, the results were expressed as nanograms of $\mathrm{TxB}_{2}$ per $10^{6}$ thrombocytes. The site of the sampling had no effect on the platelets' capacity to generate $\mathrm{TxB}_{2}$ (aortal blood, $1.278 \pm 0.207$ versus venous blood, $1.191 \pm 0.140$ $\mathrm{ng} / 10^{6}$ platelets, $n=8$ ).

Bleeding time was measured in nine healthy term and six preterm infants and in 15 preterm infants with IRDS during the 1 st week of life, using the method of Ivy (14). Arterial $\mathrm{PO}_{2}, \mathrm{PCO}_{2}$, $\mathrm{pH}$, and base excess were determined using routine laboratory methods.

Statistical Methods. The results were subjected to the analysis of variance and $t$ testing modified by the Bonferroni method (21).

\section{RESULTS}

Platelet $\mathrm{TxB}_{2}$ production increased from the fetal value by the age of $1 \mathrm{~h}$ and was at the age of 1 day higher than that in infants of 1-3 months of age or in adults (Table 2). $\mathrm{TxB}_{2}$ on the first days of life did not differ either between the healthy term and preterm infants (Table 3 ) or between 27 and 29 weeks (1.040 \pm $0.142 \mathrm{ng} / 10^{6}$ platelets, $n=6$; mean $\pm \mathrm{SE}$ ) and 33-36 weeks $\left(0.961 \pm 0.163 \mathrm{ng} / 10^{6}\right.$ platelets, $\left.n=6\right)$ of gestational age. The platelets of asphyxiated infants generated reduced amounts of $\mathrm{TxB}_{2}$ on the 1st day of life, whereas in IRDS the $\mathrm{TxB}_{2}$ release did not differ from that in control infants (Table 3 ).

The bleeding time varied from 1.5 to $10.5 \mathrm{~min}$ and was not related to $\mathrm{TxB}_{2}$ synthesis (Fig. 1).

There was no correlation between $\mathrm{TxB}_{2}$ formation and the simultaneous arterial $\mathrm{PO}_{2}, \mathrm{PCO}_{2}, \mathrm{pH}$, or base excess in infants with birth asphyxia or IRDS. Two asphyxiated infants had tendency to bleed (bloody tracheal and gastric secretions). One of them with $\mathrm{a} \mathrm{TxB}_{2}$ production of $1.250 \mathrm{ng} / 10^{6}$ platelets subsequently died because of severe asphyxia, but no hemorrhages were found at autopsy.

The mode of delivery (vaginal delivery versus cesarean section), the birth weight and sex of the infants were not related to $\mathrm{TxB}_{2}$ generation on the 1st day of life. Neither maternal preeclampsia $(n=6)$ nor epidural analgesia during labor $(n=5)$ affected neonatal $\mathrm{TxB}_{2}$ formation on day 1 .

\section{DISCUSSION}

It is clear from our results that platelet $\mathrm{TxA}_{2}$ production is stimulated rapidly after birth. This stimulation lasts for 2-10 days, after which $\mathrm{TxA}_{2}$ formation returns to the levels seen in the cord blood or in adults. Thus, it is evident that, in studies on the significance of $\mathrm{TxA}_{2}$ in newborns, platelets from the neonate and not from the umbilical cord (18) should be used. In principle, our finding of similar $\mathrm{TxB}_{2}$ generation in cord blood and adults matches well with the data of Stuart and Allen (18). Although
Table 2. Platelet $T x B_{2}$ production $\left(n g / 10^{6}\right.$ platelets, mean \pm $S E$ ) in cord blood in healthy term infants and in adults

\begin{tabular}{lrc}
\hline Age & $n$ & $\begin{array}{c}\text { Thromboxane } \mathrm{B}_{2} \\
\text { (ng/10 } / 10^{6} \text { platelets) }\end{array}$ \\
\hline Cord blood & 22 & $0.634 \pm 0.042$ \\
Hour 1 & 9 & $1.076 \pm 0.114^{*}$ \\
Day 1 & 9 & $1.344 \pm 0.253 \dagger$ \\
Days 2-10 & 15 & $0.936 \pm 0.026$ \\
Months 1-3 & 14 & $0.881 \pm 0.099 \ddagger$ \\
Adults & 18 & $0.869 \pm 0.062 \S$ \\
\hline
\end{tabular}

$* P<0.025$.

$\dagger P<0.01$ in comparison with cord blood.

$\ddagger P<0.05$.

$\S P<0.025$ in comparison with the 1 st day value.

Table 3. Platelet $T x B_{2}$ production $\left(n g / 10^{6}\right.$ platelets, mean \pm $S E$ ) in infants with severe birth asphyxia in healthy term and preterm infants, and in infants with IRDS

\begin{tabular}{lcccc}
\hline & \multicolumn{4}{c}{ Thromboxane $\mathrm{B}_{2}\left(\mathrm{ng} / 10^{6}\right.$ platelets $)$} \\
\cline { 2 - 5 } & $n$ & Day 1 & $n$ & Days 2-10 \\
\hline Infants with birth asphyxia & 7 & $0.564 \pm 0.201^{*}$ & \\
Term infants & 9 & $1.344 \pm 0.253$ & 15 & $0.936 \pm 0.026$ \\
Preterm infants & & & & \\
$\quad$ Healthy & 10 & $1.032 \pm 0.136$ & 14 & $0.908 \pm 0.133$ \\
$\quad$ With IRDS & 19 & $1.029 \pm 0.079$ & 13 & $1.141 \pm 0.098$ \\
\hline
\end{tabular}

${ }^{*} P<0.05$ in comparison with the healthy term and preterm infants.

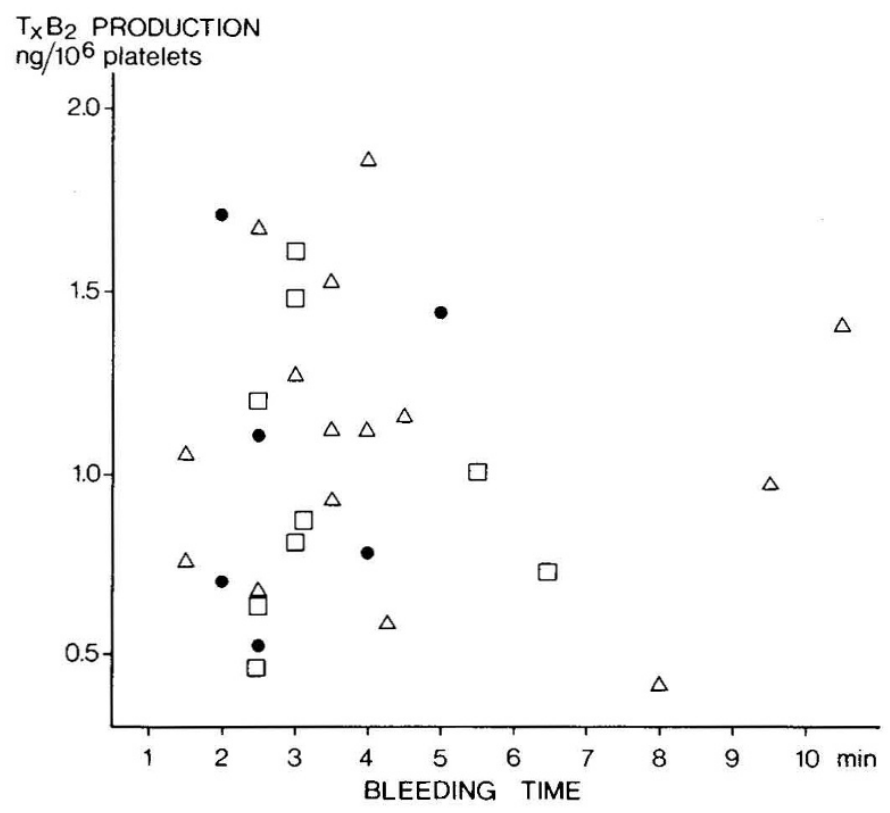

Fig. 1. Platelet $\mathrm{TxB}_{2}$ production (ng/10 $10^{6}$ platelets) in relation to the bleeding time $(\mathrm{min})$ in nine healthy term $(\square)$ and six preterm $(\bullet)$ infants and in 15 preterm infants with idiopathic respiratory distress syndrome $(\Delta)$. 
they found decreased $\mathrm{TxB}_{2}$ synthetase activity in cord blood platelets, the net $\mathrm{TxB}_{2}$ synthesis was reported to be similar in fetal and adult platelets, because precursors of $\mathrm{TxA}_{2}$ formation were increasingly available in fetal platelets (18).

With the data available, it is impossible to deduce the mechanisms behind the $\mathrm{TxA}_{2}$ stimulation in newborns, as seen in this study, but a rapid rise in oxygen tension following the start of respiration may be a contributing factor. Oxygen, on the other hand, is the primary stimulus for the postnatal closure of ductus arteriosus $(1,3)$. Taking these data together, it does not seem unlikely that oxygen could promote ductal closure by stimulating the generation of the vasoconstrictive $\mathrm{TxA}_{2}$ in neonatal platelets. It is, however, also possible that the increased $\mathrm{TxA}_{2}$ synthesis after birth may compensate for the concomitantly enhanced vascular production of the anti-aggregatory and vasodilative prostacyclin $\left(\mathrm{PGI}_{2}\right)(10,15)$, thus keeping these biologically important agents in balance.

It is well established that neonatal platelets are characterized by impaired aggregation $(8,13)$, which improves over the first weeks of life (11). The reason for this phenomenon is, however, unknown. We present here strong evidence suggesting that neonatal platelets already in the smallest preterm infants generate normal, or even increased amounts of $\mathrm{TxA}_{2}$. Thus, defective synthesis of pro-aggregatory $\mathrm{TxA}_{2}$ cannot explain the functional disturbances in neonatal platelets $(8,13)$. Furthermore, we show here for the first time that the platelets' capacity to generate $\mathrm{TxA}_{2}$ is not related to bleeding time in healthy or distressed newborns, and a similar finding was recently reported from healthy adults (19). Factors other than $\mathrm{TxA}_{2}$, perhaps changes in the membranes of the platelets (17), may account for the functional disturbances of neonatal platelets.

The infants with severe birth asphyxia had reduced platelet $\mathrm{TxA}_{2}$ generation. In effect, their $\mathrm{TxA}_{2}$ synthesis was of the same order as seen in the umbilical cord blood. The mechanisms by which asphyxia leads to inhibition of the $\mathrm{TxA}_{2}$ formation are not known. However, as in fetal life, low arterial oxygen tension may be a contributing factor, but against this explanation speaks a lacking correlation between $\mathrm{TxB}_{2}$ generation and postnatal arterial $\mathrm{PO}_{2}$. The clinical significance of the decreased $\mathrm{TxA}_{2}$ formation in asphyxiated infants remains unknown, although it may contribute to hemorrhages in these infants (7).

In view of reduced $\mathrm{TxA}_{2}$ in birth asphyxia, it was curious that infants with severe IRDS, who often are hypoxemic, had normal $\mathrm{TxA}_{2}$ in our study. The clinical signs of IRDS usually become manifest in the first few hours of life (12). The lag period with rather adequate oxygenation may be long enough to restore the $\mathrm{TxA}_{2}$ biosynthesis to the normal neonatal level. It is, however, known that the production of the $\mathrm{TxA}_{2}$ antagonist prostacyclin is increased during the acute phase of IRDS (9). Thus, the balance between $\mathrm{TxA}_{2}$ and $\mathrm{PGI}_{2}$ is shifted to a dominance of the antiaggregatory $\mathrm{PGI}_{2}$, which change may favor the manifestation of hemorrhages in IRDS. However, many other factors could also contribute to a bleeding tendency in distressed infants (7).

In conclusion, platelet $\mathrm{TxA}_{2}$ production increases rapidly after birth in healthy term and preterm infants and in infants with IRDS. Such a rise is not seen in severe birth asphyxia.

\section{REFERENCES AND NOTES}

1. Assali NS, Morris JA, Smith RW, Manson WA 1963 Studies on ductus arteriosus circulation. Circ Res 13:478

2. Bleyer WA, Hakami N, Shepard TH 1971 The development of hemostasis in the human fetus and newborn infant. J Pediatr 79:838

3. Coceani F, Olley PM 1982 Prostaglandins and the circulation at birth. In Herman AG, Vanhoutte PM, Goosens A (eds) Cardiovascular Pharmacology of the Prostaglandins. Raven Press, New York, pp 303-314

4. Granström E, Diczfalusy U, Hamberg M, Hansson G, Malmsten C, Samuelsson B 1982 Thromboxane $A_{2}$ : biosynthesis and effects on platelets. In: Oates JA (ed) Prostaglandins and the Cardiovascular System, Advances in Prostaglandin, Thromboxane, and Leukotriene Research, Vol 10. Raven Press, New York, p 15

5. Hamberg M, Svensson J, Samuelsson B 1975 Thromboxanes: a new group of biologically active compounds derived from prostaglandin endoperoxides. Proc Natl Acad Sci USA 72:2994

6. Hathaway WE 1970 Coagulation problems in the newborn infant. Pediatr Clin N Am 17:929

7. Hathaway WE 1975 The bleeding newborn. Semin Hematol 12:175

8. Hrodek O 1966 Blood platelets in the newborn. Acta Univ Carol Monogr XXII

9. Kääpä P, Koivisto M, Viinikka L, Ylikorkala O 1982 Increased plasma immunoreactive 6-keto-prostaglandin $\mathrm{F}_{1 \alpha}$ levels in newborns with idiopathic respiratory distress syndrome. Pediatr Res 11:827

10. Kääpä P, Viinikka L, Ylikorkala O 1982 Plasma prostacyclin from birth to adolescence. Arch Dis Child 57:459

11. Maak B, Frenzel J, Rogner G 1972 Aggregation of blood platelets and clot retraction in mature and premature infants. $Z$ Kinderheilk 11:325

12. Mannino FL, Gluck L 1979 The management of respiratory distress syndrome In: Thibeault DW, Gregory GA (eds) Neonatal Pulmonary Care. AddisonWesley Publishing Co, Menlo Park, Ca, pp 261-276

13. Mull MM, Hathaway WE 1970 Altered platelet function in newborns. Pediat Res $4: 229$

14. Oski FA, Naiman JL 1982 Hematologic Problems in the Newborn. WB Saunders Co, Philadelphia

15. Scherer B, Fischer S, Siess W, Weber PC 1982 Analysis of 6-ketoprostaglandin $F_{1 \alpha}$ in human urine: age-specific differences. Prostaglandins. 23:41

16. Setzer ES, Webb IB, Wassenaar JW, Reeder JD Mehta PS, Eitzman DW 1982 Platelet dysfunction and coagulopathy in intraventricular hemorrhage in the premature infant. J Pediatr 100:509

17. Stuart MJ 1979 Platelet function in the neonate. Am J Pediatr Hematol Oncol $1: 227$

18. Stuart MJ, Allen JB 1982 Arachidonic acid metabolism in the neonatal platelet. Pediatrics 69:714

19. Thorngren M, Shafi S, Born GVR 1983 Thromboxane $A_{2}$ in skin-bleedingtime blood and in clotted venous blood before and after administration of acetylsalicyclic acid. Lancet 1:1075

20. Viinikka L, Ylikorkala O 1980 Measurement of thromboxane $B_{2}$ in human plasma or serum by radioimmunoassay. Prostaglandins 20:759

21. Wallenstein S, Zucker CL, Fleiss JL 1980 Some statistical methods useful in circulation research. Circ Res 47:1

22. Whaun JM 1973 The platelet of the newborn infant. 5-Hydroxy-tryptamine uptake and release. Throm Diath Haemorrh 30:327

23. This study was supported by the Medical Research Council, The Academy of Finland.

24. Correspondence may be addressed to Pekka Kääpä, Department of Pediatrics, University of Oulu, SF-90220 Oulu 22, Finland.

25. Received for publication January 2, 1984. 